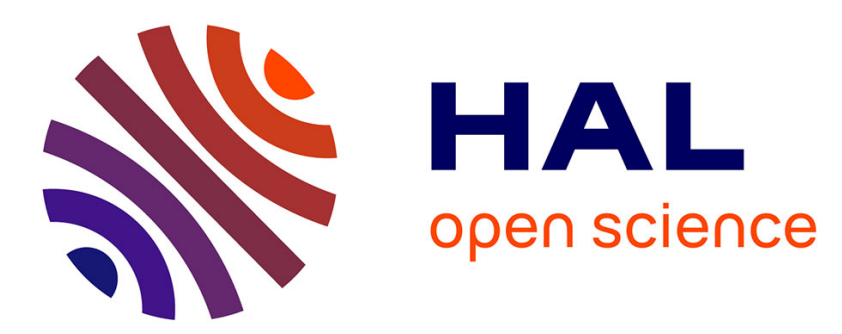

\title{
Minimum predicted distance Applying a common metric to collision avoidance strategies between children and adult walkers
}

Victoria Rapos, Michael Cinelli, Natalie Snyder, Armel Crétual, Anne-Hélène Olivier

\section{To cite this version:}

Victoria Rapos, Michael Cinelli, Natalie Snyder, Armel Crétual, Anne-Hélène Olivier. Minimum predicted distance Applying a common metric to collision avoidance strategies between children and adult walkers. Gait \& Posture, 2019, 72, pp.16-21. 10.1016/j.gaitpost.2019.05.016 . hal-02160399

\section{HAL Id: hal-02160399}

https://hal-univ-rennes1.archives-ouvertes.fr/hal-02160399

Submitted on 1 Jul 2019

HAL is a multi-disciplinary open access archive for the deposit and dissemination of scientific research documents, whether they are published or not. The documents may come from teaching and research institutions in France or abroad, or from public or private research centers.
L'archive ouverte pluridisciplinaire HAL, est destinée au dépôt et à la diffusion de documents scientifiques de niveau recherche, publiés ou non, émanant des établissements d'enseignement et de recherche français ou étrangers, des laboratoires publics ou privés. 
RUNNING HEADER: MPD WITH CHILDREN AND ADULTS

Minimum Predicted Distance: applying a common metric to collision avoidance strategies between children and adult walkers

Victoria Rapos ${ }^{1}$, Michael Cinelli $^{1}$, Natalie Snyder ${ }^{1}$, Armel Crétual $^{2}$, \& Anne-Hélène Olivier ${ }^{2}$

${ }^{1}$ Dept. of Kinesiology \& Physical Education, Wilfrid Laurier University, Waterloo, ON, Canada

${ }^{2}$ Laboratoire Mouvement Sport Sante’ (M2S), UFRAPS, Universite’ Rennes 2-ENS Cachan, Avenue Charles Tillon, CS24414, 35044 Rennes, France

Please address correspondence to

Michael E. Cinelli, PhD

Department of Kinesiology and Physical Education

Wilfrid Laurier University

75 University Ave, W. Rm. 501

Waterloo, ON, CA

mcinelli@wlu.ca 
MPD WITH CHILDREN AND ADULTS

\section{Research Highlights:}

- Tested collision avoidance strategies between middle-aged children and adults

- Minimum Predicted Distance (MPD) is a metric describing risk of collision over time

- MPD can be used to predict future collisions in middle-aged children

- MPD is consistently lower when a child is involved compared to adults

- Regardless of age the walker passing second contributes more to MPD than walker one

\section{Abstract:}

\section{Background:}

Collision avoidance between two walkers involves a mutual adaptation to speed and orientation in order to successfully avoid a collision. Minimum Predicted Distance (MPD) is the distance at which two walkers would collide if their speed and path trajectory were maintained at first sight of one another. MPD has been used to describe the risk of collision and its evolution over time between two adult walkers when on a collision course. Middle-aged children have been shown to have poor perception-action coupling during static and dynamic collision avoidance tasks. Research has yet to examine whether perception-action coupling deficits persist in a dynamic collision avoidance task involving a child and another walker.

\section{Research Question:}

Can the metric $\operatorname{MPD}(\mathrm{t})$ be used to examine collision avoidance strategies between children and adults?

Methods:

Eighteen children (age: $10 \pm 1.5$ years) and eighteen adults ( $34 \pm 9.6$ years) walked along a $12.6 \mathrm{~m}$ pathway while avoiding another participant (child or adult). Groups of three children and three adults were recruited per session. Trials were randomized equally such that each adult interacted with another adult 20 times, each child interacted with another child 20 times, and 
MPD WITH CHILDREN AND ADULTS

each adult interacted with a child 21 times, for a total of 141 trials. 3D kinematic data of each participant's head was recorded using the Vicon system.

$\underline{\text { Results: }}$

The results demonstrated: (1) MPD(t) can be used to predict future collisions in children, (2) $\mathrm{MPD}(\mathrm{t})$ is an absolute measure that is consistently lower when a child is involved compared to two adult walkers, (3) the individual passing second, even when it is a child, contributes more to $\operatorname{MPD}(\mathrm{t})$ than the walker passing first.

\section{Significance:}

It appears children have developed adult-like strategies during a collision avoidance task involving two walkers. Body anthropometrics should be considered when determining collision avoidance strategies between children and adults.

\section{Introduction:}

Vision is the primary sensory system to provide rich environmental information at a distance to determine appropriate collision avoidance strategies with obstacles[1-2]. Visual information in the form of optic flow informs observers about their rate and direction of movement within an environment as well as the movement of an environment relative to them[3]. In addition, retinal expansion of an object can be used to estimate an individual's timeto-collision (TTC) with an obstacle by detecting velocities and angles[4]. TTC can be predicted between two walkers up to 10 seconds prior to contact based on gaze angles, becoming more accurate as contact time decreases[5-6]. Visual information is then used to alter one's locomotor behaviour to successfully avoid an approaching obstacle. When considering collision avoidance between two walkers, TTC does not consider the mutual adaption required between the two walkers to successfully avoid one another. 
MPD WITH CHILDREN AND ADULTS

Collision avoidance strategy between two adult walkers is the result of mutually controlling their Minimal Predicted Distance (MPD)[7]. MPD accurately predicts the distance at which two walkers would collide if their speed and path trajectory were maintained at first sight of one another[7-9]. MPD calculation can be broken down into three successive stages: 1) observation phase, first sight of one another and MPD is low (i.e., a change in speed and trajectory is required in order to avoid a collision); 2) reactive phase, both individuals adapt their speed and trajectories to avoid a collision (i.e., MPD increases to $1.0 \mathrm{~m}$ between the centre of the two young adult walkers[7]); and 3) regulation phase, the maintenance of MPD (i.e., the two walkers ensuring a collision does not occur).

Collision avoidance between two young adult walkers on a 90 degree collision course also involves role-dependent strategies. The decision of which walker crosses in front is mutually determined by the two walkers' path trajectories and velocities, which involves one walker increasing or maintaining their velocity to cross first while the other walker reduces their velocity and/or orientation to cross second[8-9]. The mutual interaction between two walkers is dependent on the visual information perceived by the two walkers allowing for successful collision avoidance behaviours[10].

By 8-12 years old children are expected to be cognitively developed and have adult-like postural control during locomotion[11]. Obstacle avoidance behaviours in children reveals high variability and different adaptive strategies compared to young adults[12-13]. During obstacle circumvention tasks, children alter their gait patterns just prior to reaching the obstacle whereas adults make anticipatory adjustments well in advance to the obstacle[13]. Moreover, children are highly variable with their avoidance behaviours and require a larger safety margin during obstacle avoidance tasks such as passing through apertures[14-15]. Variability in obstacle 
MPD WITH CHILDREN AND ADULTS

avoidance behaviours may be due to an underdeveloped neuromuscular and/or cognitive systems[16]. It appears that middle-aged children have not fully developed adult-like obstacle avoidance strategies. However, these results have focused on children's collision avoidance strategies with respect to stationary obstacles and there is a lack of research regarding collision avoidance strategies of an approaching walker. Although collision avoidance in a dynamic context happens daily, it is unknown whether middle-aged children have developed adult-like behaviour of mutually contributing to the avoidance of an approaching walker.

The purpose of the current study was to investigate collision avoidance strategies between adults and children and to determine whether MPD can be used to predict potential collisions in children. It was hypothesized that since children have highly variable behaviours, adults will cross second because it would allow them to see the child pass in front making it safer, reducing the risk of a collision. It was also hypothesized that MPD could predict potential collisions in children, but there would be a smaller clearance distance when on a collision course with another child and a larger clearance distance when on a collision course with an adult due to the threat of injury with someone larger.

\section{Methods:}

\section{Participants}

Eighteen children (10years $\pm 1.5,146.6 \mathrm{~cm} \pm 11.7,8$ females) and eighteen adults (34years $\pm 9.6,170.7 \mathrm{~cm} \pm 11.1,11$ females) with normal or corrected to normal vision and no known neurological disorders participated in the study (Table 1). Each adult participant provided informed written consent and the children provided informed assent. The study was reviewed and accepted by the Comité de Protection des Personnes, France (2018-A00503-52) and Wilfrid Laurier University’s Research Ethics Board. 
MPD WITH CHILDREN AND ADULTS

\section{Experimental Design}

The study was performed in a $9 \mathrm{mx} 9 \mathrm{~m}$ space with 4 occluding walls that acted as barriers to allow participants to reach steady state locomotion prior to knowing who they were interacting with and from which direction that person was walking (Figure 1). Each experimental session consisted of three children and three adults located at the four corners of the experimental space. 3D kinematic data was recorded using the Vicon system at a sampling rate of $120 \mathrm{~Hz}$. In order to track each participant's movement, they wore helmets containing 4 reflective markers to represent a rigid body unique to each participant's head.

\section{Protocol}

Participants were instructed to walk at their normal pace toward the opposite corner while avoiding another walker. One baseline walking trial was completed for each participant to determine individual walking speeds and start locations to ensure interactions between participants occurred on every trial in the center of the experimental space. Participant's walking at a slower walking speed were asked to take 1-2 steps closer from the starting position in order to increase the likelihood an interaction would occur in the center of the experimental space.

Each trial required two participants, not sharing the same diagonal, to reach their opposite corner while avoiding one another. Trials were randomized and included the following interactions: 1) 30 adult-adult (AA), 2) 63 adult-child (AC), 3) 30 child-child (CC), and 4) control trials in which only one participant walked to the opposite corner of the experimental space. Each participant interacted with individuals from the same group 20 times and interacted with the opposite group 21 times. To ensure everyone had a chance to interact with one another, six block trials consisting of 24 randomized trials each, consisting of $\mathrm{AA}, \mathrm{AC}, \mathrm{CC}$, and individual trials, were completed for a total of 141 trials. 
MPD WITH CHILDREN AND ADULTS

\section{Data Analysis}

The location of the rigid body on each participant's head at each time point was used to compute MPD and the velocity of each participant. Data were smoothed using a $0.5 \mathrm{~Hz}$ low pass $2^{\text {nd }}$ order Butterworth filter to remove high stepping oscillations. Velocity was computed using the time derivative of the participant's location.

MPD was computed at each instant of time $(t)$ such that $\operatorname{MPD}(t)$ represented the distance at which the two participants would meet if no speed or path adaptation occurred at that instant in time[7]. For all analyses, trials were separated into the following four groups based on the interaction and who crossed first: 1) adult-adult (AA), 2) child-child (CC), 3) child-adult passing second (CA), and 4) adult-child passing second (AC). Trials were successfully reconstructed from the time individuals first saw one another (tsee) to the time of crossing (tcross). $\operatorname{MPD}($ tsee) is the initial predicted distance of crossing at time tsee, when participants crossed the occluding walls and could first see one another, MPD(tcross) occurs at dmin, the minimum distance between the two participants at time of crossing.

$\operatorname{MPD}(t)$ is a positive progression measured from the center of one individual to the center of the other individual. A negative $\operatorname{MPD}($ tsee $)$ means an inversion in walking order occurred such that walker \#1 was intended to pass first however stopped to allow walker \#2 to pass first. Inversions of $\mathrm{MPD}(\mathrm{t})$, when tsee was negative, were subsequently removed from further analyses. To ensure an adaptation to an individual's collision avoidance strategy occurred, a threshold was determined by subdividing data at $\operatorname{MPD}($ tsee $)$ by $0.1 \mathrm{~m}$ in ascending order and compared to MPD(tcross). Within each interaction group $\operatorname{MPD}($ tsee $)$ values were subdivided into bins of $0.1 \mathrm{~m}$ based on ascending $\operatorname{MPD}($ tsee) values (Figure 2). 
MPD WITH CHILDREN AND ADULTS

A temporal normalization of the interaction from tsee to tcross was conducted for each trial to enable comparisons. Temporal normalization normalizes the progression of MPD to a percent of time. Adaptations in $\operatorname{MPD}(t)$ by the walker passing first (participant \#1) were examined relative to the participant giving way (participant \#2)[8]. Collision avoidance strategies were analyzed on the normalized reaction phase and avoidance strategies were compared between groups. Contributions to $\operatorname{MPD}(t)$ of each walker were revealed by computing the partial derivatives of $\operatorname{MPD}(t)$ relative to motion adaptations performed by participants as calculated in Olivier et al. [8]. The partial derivative calculation allowed to determine how much adaption to $\operatorname{MPD}(t)$ occurred when speed or path orientation varied between the two walkers. When determining the contribution of each walker, trials were valid when there was a minimum change of $0.05 \mathrm{~m}$ between MPD(tsee) and MPD(tcross) as anything less would be too small of a change for an individual to change their behaviour.

\section{Statistical Analysis}

General linear models were conducted to determine MPD differences and crossing order differences between groups. Any $p<.05$ was deemed as significant. A paired dependent samples t-test was used to determine whether an adaptation to MPD occurred. Each group's MPD was compared at tsee and tcross to define thresholds. Significant differences between tsee and tcross would infer an adaptation to an individual's speed or path trajectory occurred in order to avoid a collision. Statistical Parametric Mapping (SPM, cf ref Friston) with post-hoc analysis was conducted in order to compare the difference in the evolution of MPD between groups from tsee to tcross. To compare the contribution of collision avoidance between participants during any given trial, an independent samples t-test using SPM were completed.

\section{$\underline{\text { Results: }}$}


MPD WITH CHILDREN AND ADULTS

No collisions occurred throughout the entire experiment. There was no significant difference between adult's $(1.52 \mathrm{~m} / \mathrm{s} \pm 0.14)$ and children's $(1.53 \mathrm{~m} / \mathrm{s} \pm 0.18)$ walking velocities (p>.05). The mean clearance distance $(d \min )$ for the trials when an adaptation to an individual's collision avoidance strategies were: $0.77 \mathrm{~m}( \pm 0.15 \mathrm{~m})$ for AA; $0.67 \mathrm{~m}( \pm 0.15 \mathrm{~m})$ for $\mathrm{CA} ; 0.71 \mathrm{~m}$ $( \pm 0.15 \mathrm{~m})$ for $\mathrm{AC}$; and $0.58 \mathrm{~m}( \pm 0.14 \mathrm{~m})$ for $\mathrm{CC}$.

\section{Threshold determination}

For the AA interactions, when MPD(tsee) was lower than $0.9 \mathrm{~m}$ (threshold levels 0m$0.8 \mathrm{~m}), \mathrm{MPD}$ (tcross) values were significantly higher than $\mathrm{MPD}($ tsee $)$. When MPD(tsee) ranged from $0.9 \mathrm{~m}$ to $1.0 \mathrm{~m}$, there was no significant different between MPD(tcross) and MPD(tsee) (p>.05). When MPD(tsee) was $1.1 \mathrm{~m}$ and greater, MPD(tcross) was significantly higher than MPD (tsee) (Table 2A).

For the CC interactions, when $\mathrm{MPD}($ tsee) was lower than $0.7 \mathrm{~m}$ (threshold levels $0 \mathrm{~m}$ 0.6m), MPD(tcross) values were significantly higher than $\operatorname{MPD}($ tsee $)$. When $\mathrm{MPD}($ tsee $)$ was $0.7 \mathrm{~m}, 0.8 \mathrm{~m}$, and $1.0 \mathrm{~m}$ there was no significant difference between $\mathrm{MPD}$ (tcross) and $\mathrm{MPD}($ tsee $)$. When MPD(tsee) was $0.9 \mathrm{~m}$ and $1.1 \mathrm{~m}$ and above, MPD(tcross) was significantly lower than $\operatorname{MPD}($ tsee $)$ (Table 2B).

For the CA interactions, when MPD(tsee) was lower than $0.8 \mathrm{~m}$ (threshold levels 0m0.7m), MPD(tcross) values were significantly higher than MPD(tsee). When MPD(tsee) was

$0.8 \mathrm{~m}$ to $1.0 \mathrm{~m}$ there was no significant difference between $\mathrm{MPD}$ (tcross) and $\mathrm{MPD}($ tsee $)$. When MPD(tsee) was $1.1 \mathrm{~m}$ and above, MPD(tcross) was significantly lower than MPD(tsee) (Table 2C).

For the AC interactions, when $\mathrm{MPD}($ tsee $)$ was lower than $0.8 \mathrm{~m}$ (threshold levels 0m0.7m), MPD(tcross) values were significantly higher than $\mathrm{MPD}($ tsee $)$. When $\mathrm{MPD}($ tsee $)$ was 
MPD WITH CHILDREN AND ADULTS

$0.8 \mathrm{~m}$ to $0.9 \mathrm{~m}$ there was no significant difference between $\operatorname{MPD}($ tcross $)$ and $\operatorname{MPD}($ tsee $)$. When MPD(tsee) was higher than 1.0m, MPD(tcross) was significantly lower than MPD(tsee) (Table 2D).

Results revealed that walkers adapted their trajectories to increase $\operatorname{MPD}(t)$ when $\mathrm{MPD}($ tsee $)$ was lower than $0.9 \mathrm{~m}$ for the AA trials; $0.8 \mathrm{~m}$ for the $\mathrm{CA}$ and AC trials; and $0.7 \mathrm{~m}$ for the CC trials. Only trials below each group's thresholds were analyzed and the overall mean $\overline{M P D}(t)$ and its time derivative were computed.

Minimum Predicted Distance (MPD)

SPM analysis revealed a significant difference of $\operatorname{MPD}(t)$ between groups (Figure 3A). Post-hoc analysis revealed a significant difference throughout the entire evolution of MPD $(t)$ between AA and CC trials $(t>2.312, p<.001)$; AA and CA trials $(\mathrm{t}>2.283, \mathrm{p}=.002) ; \mathrm{CC}$ and AC trials $(\mathrm{t}>2.344, \mathrm{p}<.001) ; \mathrm{CC}$ and CA trials $(\mathrm{t}>2.344, \mathrm{p}<0.001)$. There were also significant differences in the regulation phase of $\operatorname{MPD}(\mathrm{t})(80 \%$ to $100 \%$ of the interaction) between AA and AC trials ( $(>2.299, \mathrm{p}=.043)$ and during the reactive phase of $\operatorname{MPD}(t)(10 \%$ to $80 \%$ of the interaction) between $\mathrm{AC}$ and $\mathrm{CA}$ trials $(\mathrm{t}>2.30, \mathrm{p}=.038)$ (Figure 2). When comparing MPD(tcross), there was a statistically significant difference of clearance distance between groups $\left(\mathrm{F}(3,1)=28.66, \mathrm{p}<.001, n^{2}=0.156\right)$. Post hoc analysis showed no significant difference between the clearance distance of CA $(\operatorname{MPD}($ tcross $)=0.67 \mathrm{~m})$ and $\mathrm{AC}$ groups $(\mathrm{MPD}($ tcross $)=0.71 \mathrm{~m})$. All other comparisons of clearance distance were statistically different from one another (AA $\operatorname{MPD}($ tcross $)=0.77 \mathrm{~m}, \mathrm{CC} \operatorname{MPD}($ tcross $)=0.58 \mathrm{~m})$.

Derivative of Minimum Predicted Distance (MPD)

SPM analysis revealed a significant difference of the derivative of $\operatorname{MPD}(t)$ between groups (Figure 3B). Post-hoc analysis revealed significant differences between the observation 
phase ( $0 \%$ to $10 \%$ of the interaction) and the regulation phase ( $80 \%$ to $100 \%$ of the interaction) between AA and CC trials $(\mathrm{t}>2.846, \mathrm{p}<.001)$; AA and CA trials $(\mathrm{t}>2.837, \mathrm{p}<.001), \mathrm{CC}$ and AC trials $(\mathrm{t}>2.863, \mathrm{p}=0.002 ; \mathrm{p}<.001), \mathrm{CC}$ and $\mathrm{CA}$ trials $(\mathrm{t}>2.863, \mathrm{p}=0.002, \mathrm{p}<0.001)$. There was also a significant difference during the regulation phase ( $80 \%$ to $100 \%$ of the interaction) between $\mathrm{AC}$ and CA trials $(\mathrm{t}=2.849, \mathrm{p}<0.001)$.

\section{Contribution to collision avoidance}

When determining the contribution of each walker during the interaction (from tsee to tcross), results revealed that both walkers contributed to the increase of MPD suggesting that collision avoidance was mutually performed by both walkers. Nevertheless, contribution of walker \#2 to actively avoid a collision was greater than the contribution of walker \#1 regardless of the individual (Figure 4). There was no main effect of group between children and adults for walker \#1 and for walker \#2. There were significant differences in the contribution to increase MPD between walker \#1 and walker \#2 from $0 \%-15 \%$ of the interaction between AA $(\mathrm{t}>2.828$, $\mathrm{p}=.021) ; \mathrm{CA}(\mathrm{t}>2.819, \mathrm{p}=.017)$; and $\mathrm{AC}(\mathrm{t}>2.879, \mathrm{p}=0.036)$. There were also significant differences in the contribution to increase MPD between walker \#1 and walker \#2 from 50\%$100 \%$ of the interaction between AA $(t>2.828, p<.001)$; CA $(t>2.819, p<.001)$; and AC $(t>2.879$, $\mathrm{p}<.001)$. The CC trials only revealed significant differences during the observation phase ( $0 \%$ to $10 \%$ of the interaction) to increase MPD between the two walkers $(\mathrm{t}=2.868, \mathrm{p}=.032)$.

\section{Discussion:}

The objective of the current study was to investigate the collision avoidance strategies between children and adults. It was hypothesized that children would have smaller clearance distance when on a collision course with another child and would have larger clearance distance when on a collision course with an adult. 
MPD WITH CHILDREN AND ADULTS

$\operatorname{MPD}(t)$ was analyzed from $\mathrm{MPD}($ tsee $)$ to $\mathrm{MPD}($ tcross $)$. By grouping trials according to MPD(tsee $)$ thresholds, behaviours within groups were observed to determine whether an adaptation to $\operatorname{MPD}(t)$ occurred. $\operatorname{MPD}($ tsee $)$ thresholds differed based on which walkers were interacting with one another.

Similar to Olivier et al.[7], when two adults interacted with one another (AA), MPD(tsee) threshold was $0.9 \mathrm{~m}$ (Figure 2a). When $\mathrm{MPD}($ tsee $)$ was below $0.9 \mathrm{~m}$ adults avoided a future collision by increasing the distance between walkers in order to reach an acceptable crossing distance at the time of crossing. However, when one walker was a child, collision avoidance strategies changed. When an adult and child interacted, regardless of crossing order, MPD(tsee) threshold was $0.8 \mathrm{~m}$ suggesting that a mutual adaptation occurred to avoid a future collision at the time of crossing at a smaller distance. Although the overall progression of $\operatorname{MPD}(t)$ is similar between children and adults, person specific characteristics, such as height and body anthropometrics, may be the driving factor causing a decrease in $\operatorname{MPD}(t)$ when a child and adult interacted. In addition, anthropometrics may have also played a role when two children interacted with one another as the $\operatorname{MPD}($ tsee $)$ threshold was $0.7 \mathrm{~m}$ (i.e., adaptation occurred at a smaller distance). Throughout the entire progression of $\operatorname{MPD}(t)$ the distance was always smaller when two children interact compared to two adults (Figure 3A), most likely due to maintaining one's area of personal space[17]. The idea of personal space, the distance an individual will maintain when circumventing an obstacle (static and dynamic), is related to an individual's shoulder width and thus their relative safety margin. Compared to adults, children are typically smaller in size and consequently they have a smaller shoulder width. A child's relative safety margin may be similar to that of an adult when on a collision course however, the absolute safety margin differs due to the size of the individuals. A smaller individual possessed a smaller 
MPD WITH CHILDREN AND ADULTS

shoulder width (based on anthropometrics), resulting in a smaller absolute safety margin required to pass one another when on a collision course. Therefore, the overall decrease in $\operatorname{MPD}(t)$ may be determined by the size of the individual.

When on a collision course with an approaching walker, specific details about the approaching walker is not identified by an individual until the walker is within one's central field of view[18]. Visual acuity or fine detail about the approaching walker, such as face recognition or sex differences, are only identifiable approximately $1 \mathrm{~m}$ from one another[18]. The only thing individuals were able to recognize at the $\operatorname{MPD}($ tsee $)$ was the size of the approaching individual. Therefore, it is unlikely the differences in MPD between groups are due to sex differences or familiarity about the two walkers and more so due to the size of the individual or the stage of development.

Middle-aged children may not have a fully developed dorsal stream which is involved with information processing, resulting in a longer time required to process collision avoidance information[19-20]. Compared to young adults, children have difficulty with perception-action coupling, misjudging passable gaps[19]. A delayed response to avoid a collision may partially explain why MPD(tcross) occurs at a smaller distance when a child is involved, since they are not efficiently synchronizing motor movements with perceptual information about the environment. A delayed response results in a longer adaptation to avoid a potential collision and a smaller overall passable distance between walkers. Since $\operatorname{MPD}(t)$ is an absolute measure it is unknown whether an under-developed dorsal stream is causing a difference in $\operatorname{MPD}(t)$ or whether it's solely due to body anthropometrics. However, regardless of the overall decrease of $\operatorname{MPD}(t)$ when a child is involved, it seems children are able to resolve a potential collision similar to adults. 
In terms of walker contribution, the walker giving way (\#2) contributed more to the avoidance than the one passing first (\#1), regardless of who was interacting with one another[8]. An individual's age and size did not change the fact that walker \#2 always contributes more to the avoidance of a collision compared to walker \#1 during an interaction. Visual attention may play an essential role in determining crossing order of walkers. When an individual is fixated (attending) on the goal ahead rather than the approaching walker, they will cross first[1]. Alternatively, the individual that crosses second is aware of the approaching walker and gives way to ensure successful collision avoidance. However, gaze data was not collected and therefore we cannot confirm that visual attention determines crossing order.

In conclusion, middle-aged children appear to have developed adult-like strategies in terms of contributing to the successful avoidance of another individual when on a collision course. Middle-aged children are able to adapt to becoming an avoider during a collision course if the situation requires it, indicating proper child motor development. Therefore, collision avoidance strategies are affected by situational rather than personal characteristics (i.e., height [17]) of an approaching individual[9]. 
MPD WITH CHILDREN AND ADULTS

References:

1. Croft, J.L. \& Panchuk, D. (2017). Watch where you're going? Interferer Velocity and visual behavior predicts avoidance strategy during pedestrian encounters. Journal of Motor Behavior, 0, 1-11

2. Patla, A.E. (1997). Understanding the roles of vision in the control of human locomotion. Gait Posture, 5, 54-69

3. Gibson, J. J. 1966 The senses considered as perceptual systems. Boston: Houghton Mifflin.

4. Cinelli, M.E. \& Patla, A.E. (2007). Travel path conditions dictate the manner in which individuals avoid collisions. Gait Posture, 26, 186-193

5. Cutting J, Vishton PM, Braren PA. (1995). How do we avoid collisions with stationary and moving obstacles. Psychology Rev, 102(4), 627-51

6. Savelsbergh GJP, Whiting HTA, Bootsma RJ. (1991). Grasping tau. Journal of Experimental Psychology and Human Perception Performance, 17(2), 315-22.

7. Olivier, A-H., Marin, A., Crétual, A., \& Pettré, J. (2012). Minimal predicted distance: A common metric for collision avoidance during pairwise interactions between walkers. Gait \& Posture, 36, 399-404

8. Olivier, A-H., Marin, A., Crétual, A., Berthoz, A., \& Pettré, J. (2013). Collision avoidance between two-walkers: Role-dependent strategies. Gait \& Posture, 38, 721-756

9. Knorr, A.G., Willacker, L., Hermsdorfer, J., \& Glasauer, S. (2016). Influence of Personand Situation-Specific Characteristics on Collision Avoidance Behaviour in Human Locomotion. Journal of Experimental Psychology: Human Perception and Performance, $1-13$

10. Lynch, S. (2018). Effect if virtual human gaze behaviour during an orthogonal collision avoidance walking task. IEEE Virtual Reality, Conference paper.

11. Shumway-Cook, A. \& Woollacott, M.J. (1985). The growth of stability: postural control from a developmental perspective. Journal of Motor Behaviour, 17(2), 131-147

12. Hackney, A.L., Vallis, L.A., \& Cinelli, M.E. (2013). Action strategies of individuals during aperture crossing in nonconfined space. Quarterly Journal of Expimental Psychology (Hove), 66(6), 1104-12 
MPD WITH CHILDREN AND ADULTS

13. Vallis, L.A. \& McFadyen, B.J. (2005). Children use different anticipatory control strategies than adults to circumvent an obstacle in the travel path. Experimental Brain Research. 167, 119-127.

14. Hackney, A.L. \& Cinelli, M.E. (2011). Action strategies of older adults walking through apertures. Gait Posture, 33(4):733-736

15. Wilmut, K. \& Barnett, A.L. (2011). Locomotor behaviour of children while navigating through apertures. Exp Brain Research, 210(2): 185-94

16. van Basten, B. J., Jansen, S. E., \& Karamouzas, I. (2009). Exploiting motion capture to enhance avoidance behaviour in games. In A. Egges, R. Geraerts, \& M. Overmars (Eds.), Motion in games (pp. 29-40). Berlin, Germany: Springer.

17. Gérin-Lajoie, M., Richards, C.L. Fung, J., \& McFadyen, B.J. (2008). Characteristics of personal space during obstacle circumvention in physical and virtual environments. Gait and Posture, 27(2), 239-47

18. Kandle,E.R., Schwartz, J.H., Jessell, T.M., Siegelbaum, S.A., \& Hudspeth, A.J. (2013) Principles of Neuroscience (5th ed.). New York: McGraw-Hill, Health Professions Division

19. Plumert, J. M., Kearney, J. K., \& Cremer, J. F. (2004). Children's Perception of Gap Affordances: Bicycling Across Traffic-Filled Intersections in an Immersive Virtual Environment. Child Development, 75(4), 1243-1253

20. Plumert, J.M., Kearney, J.K., \& Cremer, J.F. (2008). Children's road crossing: a window into perceptual-motor development. Association for Psychological Science, 16(5), 255258 
Figure 1: Experimental Setup consisting of 4 occluding walls within a $9 \mathrm{mx} 9 \mathrm{~m}$ area. Two participants stand at the corners of the area and are given a start signal to walk to the opposite corner.

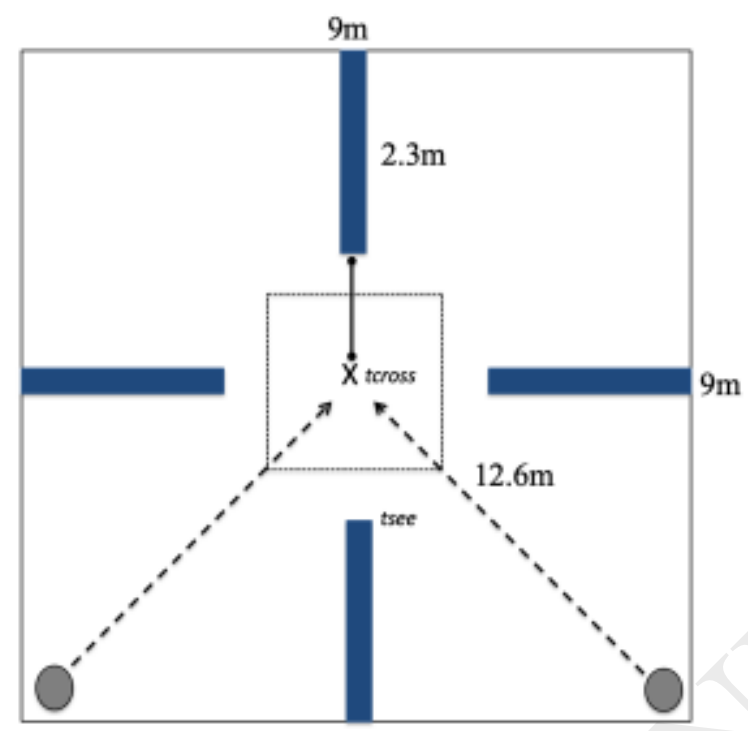

Figure 2: Mean values of MPD(tsee) and MPD(tcross) for each interaction grouping by $0.1 \mathrm{~m}$ increments for: A) adult-adult (AA) interactions, B) child-child (CC) interactions, C) child-adult $(\mathrm{CA})$ interactions, and $\mathrm{D})$ adult-child (AC) interactions. 

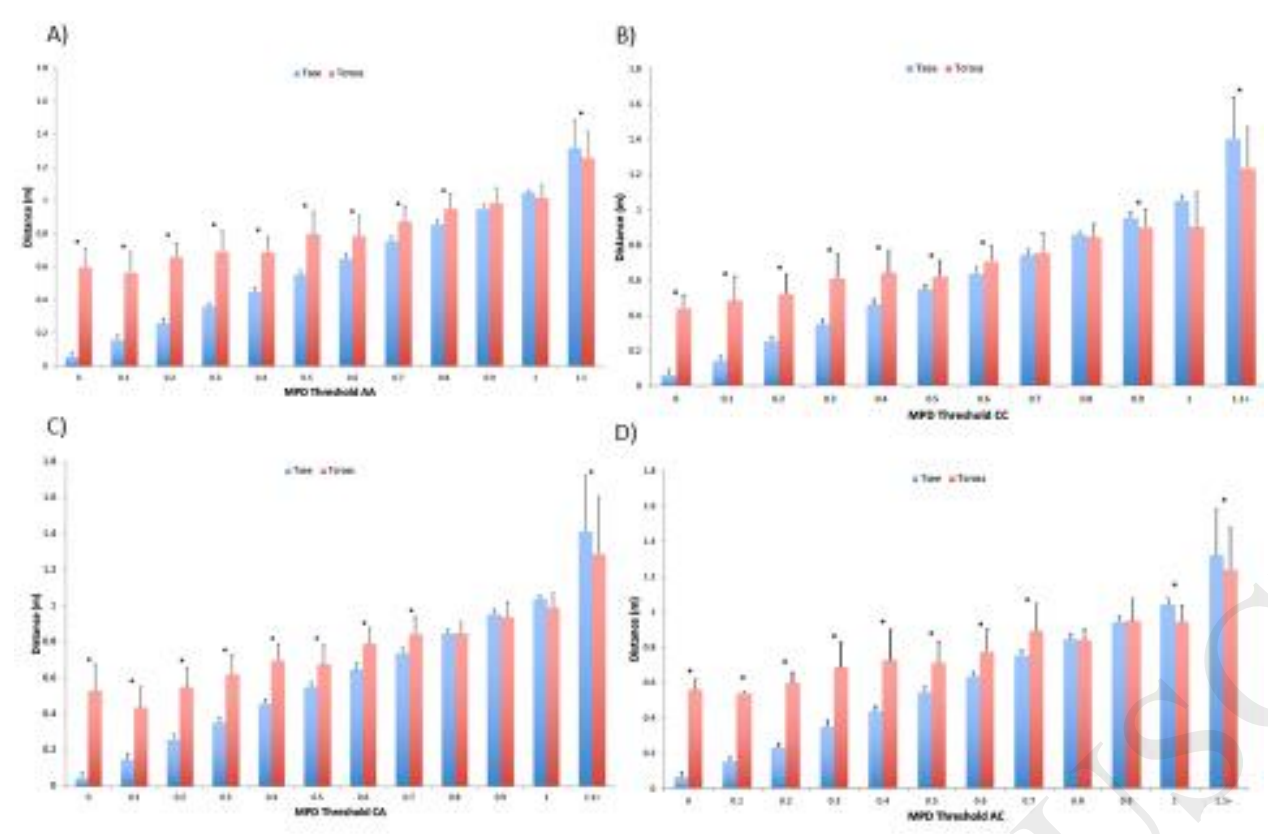

D)

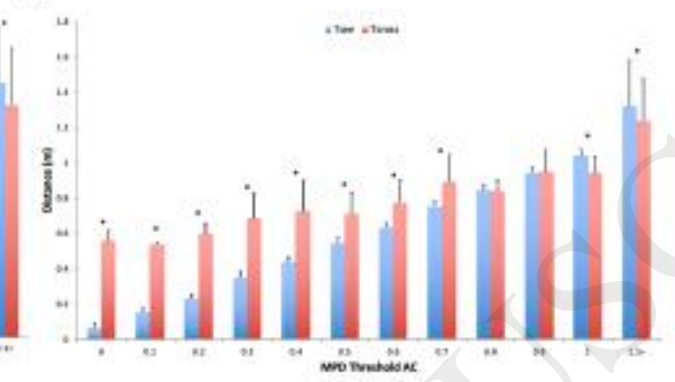

Figure 3. A) Mean $\operatorname{MPD}(t)$ evolution over time without an inversion for each group and $\mathrm{B}) \mathrm{MPD}(t)$ time derivative for each group without an inversion. The shaded areas represent the subject variability within in each group.
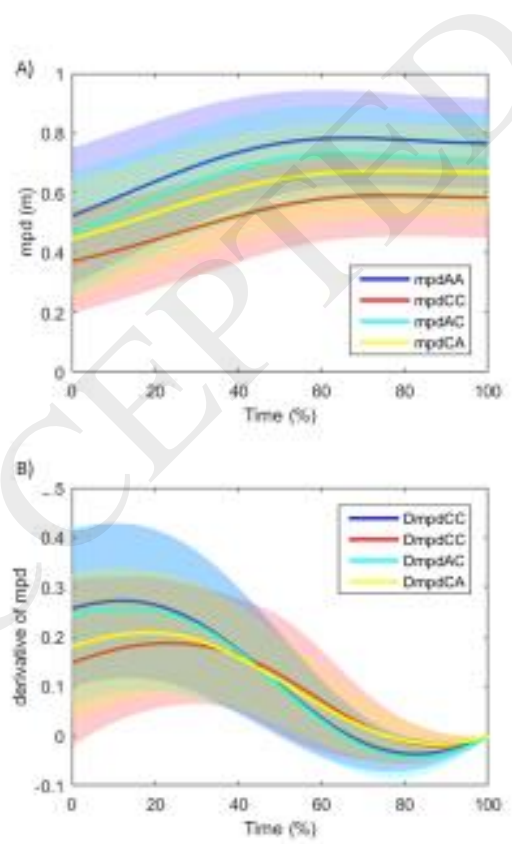
Figure 4. Contribution (mean and SD) to MPD between walker \#1 and walker \#2 between A) adult adult interactions, B) child- adult interactions, C) adult- child interactions, and D) childchild interactions.
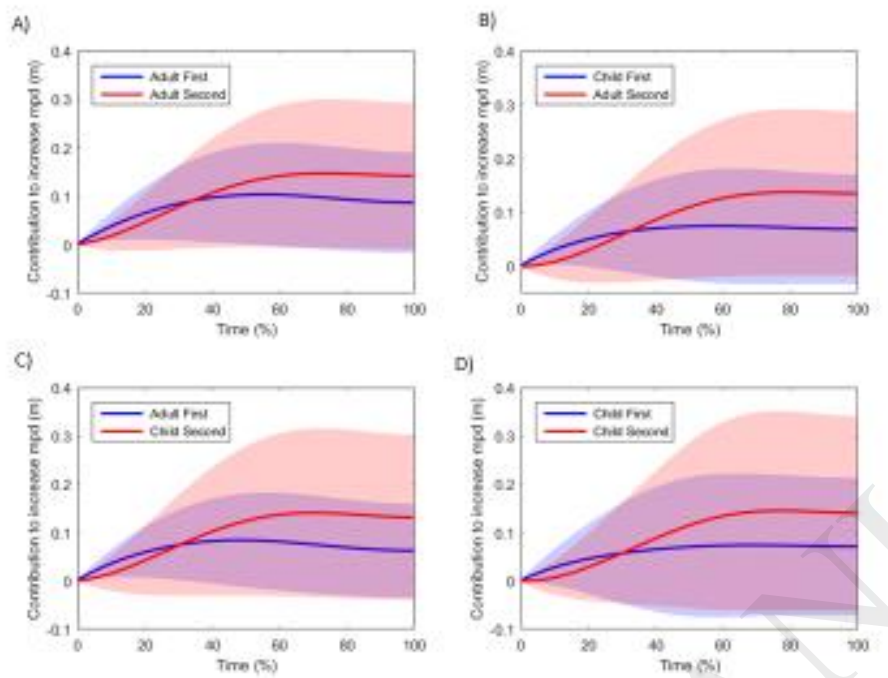
Table 1: Characteristics of the participants including age, sex, and height

\begin{tabular}{|c|c|c|c|c|c|c|c|}
\hline YA & AGE & SEX & $\begin{array}{l}\text { HEIGHT } \\
(\mathrm{cm})\end{array}$ & KIDS & AGE & SEX & $\begin{array}{l}\text { HEIGHT } \\
(\mathrm{cm})\end{array}$ \\
\hline 1 & 27 & $M$ & 167 & 1 & 13 & $M$ & 135 \\
\hline 2 & 46 & $\mathrm{~F}$ & 160 & 2 & 11 & $\mathrm{M}$ & 146 \\
\hline 3 & 39 & $\mathrm{~F}$ & 169 & 3 & 8 & $\mathrm{M}$ & 152 \\
\hline 4 & 25 & $\mathrm{~F}$ & 179 & 4 & 12 & $\mathrm{M}$ & 164 \\
\hline 5 & 36 & $M$ & 152 & 5 & 12 & $\mathrm{~F}$ & 166 \\
\hline 6 & 34 & $\mathrm{~F}$ & 148 & 6 & 9 & $\mathrm{M}$ & 152 \\
\hline 7 & 19 & $\mathrm{~F}$ & 180 & 7 & 12 & $\mathrm{M}$ & 168 \\
\hline 8 & 27 & $\mathrm{~F}$ & 169 & 8 & 8 & $\mathrm{~F}$ & 131 \\
\hline 9 & 37 & $M$ & 183 & 9 & 9 & $\mathrm{~F}$ & 131 \\
\hline 10 & 47 & $\mathrm{~F}$ & 175 & 10 & 12 & $\mathrm{M}$ & 138 \\
\hline 11 & 27 & $\mathrm{~F}$ & 177 & 11 & 11 & $\mathrm{M}$ & 155 \\
\hline 12 & 42 & $\mathrm{M}$ & 170 & 12 & 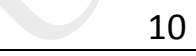 & $\mathrm{F}$ & 139 \\
\hline 13 & 47 & $\mathrm{~F}$ & 170 & 13 & 9 & $\mathrm{~F}$ & 136 \\
\hline 14 & 26 & $\mathrm{M}$ & 186 & 14 & 12 & $\mathrm{~F}$ & 146 \\
\hline 15 & 50 & $\mathrm{~F}$ & 169 & 8 & 12 & $\mathrm{~F}$ & 155 \\
\hline 16 & 24 & $M$ & 189 & $Y$ & 10 & $\mathrm{~F}$ & 147 \\
\hline 17 & 24 & $M$ & 158 & 17 & 10 & $\mathrm{M}$ & 138 \\
\hline 18 & 37 & $\mathrm{~F}$ & 172 & 18 & 10 & $\mathrm{M}$ & 139 \\
\hline Mean & 34.11 & & 170.72 & & 10.56 & & 146.56 \\
\hline SD & 9.6 & & 11.11 & & 1.54 & & 11.72 \\
\hline
\end{tabular}


Table 2: Dependent t-test and p-values of thresholds between 0-1.1 m distance: A) AA interactions, B) CC interactions,

C) CA interactions, and D) AC interactions

\begin{tabular}{|c|c|c|c|c|c|}
\hline $\begin{array}{c}\text { AA Threshold } \\
(\mathrm{m})\end{array}$ & t Statistic & p-value & CC Threshold (m) & t Statistic & p-value \\
\hline 0 & $t(7)=-12.59$ & $<0.01$ & 0 & $t(5)=-13.15$ & $<0.01$ \\
\hline 0.1 & $t(3)=-17.39$ & $<0.01$ & 0.1 & $t(9)=-7.43$ & $<0.01$ \\
\hline 0.2 & $\begin{array}{c}t(12)=- \\
17.39\end{array}$ & $<0.01$ & 0.2 & $t(21)=-12.27$ & $<0.01$ \\
\hline 0.3 & $\begin{array}{c}t(22)=- \\
13.35\end{array}$ & $<0.01$ & 0.3 & $t(13)=-7.02$ & $<0.01$ \\
\hline 0.4 & $t(8)=-6.58$ & $<0.01$ & 0.4 & $t(15)=-6.23$ & $<0.01$ \\
\hline 0.5 & $t(21)=-8.43$ & $<0.01$ & 0.5 & $t(14)=-2.88$ & $<0.01$ \\
\hline 0.6 & $t(19)=-5.51$ & $<0.01$ & 0.6 & $t(10)=-2.61$ & 0.03 \\
\hline 0.7 & $t(19)=-6.30$ & $<0.01$ & 0.7 & $t(13)=-7.02$ & 0.74 \\
\hline 0.8 & $t(15)=-4.15$ & $<0.01$ & 0.8 & $t(6)=0.43$ & 0.68 \\
\hline 0.9 & $t(10)=-1.26$ & 0.24 & 0.9 & $t(17)=2.15$ & 0.05 \\
\hline 1 & $t(4)=0.87$ & 0.44 & 1 & $t(7)=2.22$ & 0.06 \\
\hline 1.1 & $t(14)=2.92$ & $<0.01$ & 1.1 & $t(26)=5.89$ & $<0.01$ \\
\hline $\begin{array}{c}\text { AC Threshold } \\
(\mathrm{m})\end{array}$ & t Statistic & p-value & CA Threshold (m) & t Statistic & p-value \\
\hline 0 & $t(7)=-22.29$ & $<0.01$ & 0 & $t(6)=-9.14$ & $<0.01$ \\
\hline 0.1 & $t(2)=-20.56$ & $<0.01$ & 0.1 & $t(8)=-7.11$ & $<0.01$ \\
\hline 0.2 & $t(9)=-17.08$ & $<0.01$ & 0.2 & $t(13)=-9.43$ & $<0.01$ \\
\hline 0.3 & $t(15)=-9.53$ & $<0.01$ & 0.3 & $t(37)=-15.16$ & $<0.01$ \\
\hline 0.4 & $t(15)=-6.55$ & $<0.01$ & 0.4 & $t(17)=-11.43$ & $<0.01$ \\
\hline 0.5 & $t(20)=-6.21$ & $<0.01$ & 0.5 & $t(11)=-3.68$ & $<0.01$ \\
\hline 0.6 & $t(14)=-4.62$ & $<0.01$ & 0.6 & $t(22)=-7.00$ & $<0.01$ \\
\hline 0.7 & $t(11)=-3.26$ & $<0.01$ & 0.7 & $t(18)=-5.29$ & $<0.01$ \\
\hline 0.8 & $t(11)=0.281$ & 0.78 & 0.8 & $t(19)=0.02$ & 0.98 \\
\hline 0.9 & $t(10)=-0.07$ & 0.94 & 0.9 & $t(19)=1.07$ & 0.3 \\
\hline 1 & $t(6)=2.47$ & 0.05 & 1 & $t(9)=2.22$ & 0.05 \\
\hline 1.1 & $t(21)=2.86$ & $<0.01$ & 1.1 & $t(33)=7.86$ & $<0.01$ \\
\hline
\end{tabular}


B)

\begin{tabular}{|c|c|c|}
\hline CC Threshold (m) & t Statistic & $p$-value \\
\hline 0 & $t(5)=-13.15$ & $<0.01$ \\
\hline 0.1 & $t(9)=-7.43$ & $<0.01$ \\
\hline 0.2 & $t(21)=-12.27$ & $<0.01$ \\
\hline 0.3 & $t(13)=-7.02$ & $<0.01$ \\
\hline 0.4 & $t(15)=-6.23$ & $<0.01$ \\
\hline 0.5 & $t(14)=-2.88$ & $<0.01$ \\
\hline 0.6 & $t(10)=-2.61$ & 0.03 \\
\hline 0.7 & $t(13)=-7.02$ & 0.74 \\
\hline 0.8 & $t(6)=0.43$ & 0.68 \\
\hline 0.9 & $t(17)=2.15$ & 0.05 \\
\hline 1 & $t(7)=2.22$ & 0.06 \\
\hline 1.1 & $t(26)=5.89$ & $<0.01$ \\
\hline CA Threshold (m) & t Statistic & p-value \\
\hline 0 & $t(6)=-9.14$ & $<0.01$ \\
\hline 0.1 & $t(8)=-7.11$ & $<0.01$ \\
\hline 0.2 & $t(13)=-9.43$ & $<0.01$ \\
\hline 0.3 & $t(37)=-15.16$ & $<0.01$ \\
\hline 0.4 & $t(17)=-11.43$ & $<0.01$ \\
\hline 0.5 & $t(11)=-3.68$ & $<0.01$ \\
\hline 0.6 & $t(22)=-7.00$ & $<0.01$ \\
\hline 0.7 & $t(18)=-5.29$ & $<0.01$ \\
\hline 0.8 & $t(19)=0.02$ & 0.98 \\
\hline 0.9 & $t(19)=1.07$ & 0.3 \\
\hline 1 & $t(9)=2.22$ & 0.05 \\
\hline 1.1 & $t(33)=7.86$ & $<0.01$ \\
\hline
\end{tabular}


C)

\begin{tabular}{|c|c|c|c|c|c|}
\hline $\begin{array}{l}\text { AA Threshold } \\
(\mathrm{m})\end{array}$ & t Statistic & p-value & CC Threshold (m) & t Statistic & p-value \\
\hline 0 & $t(7)=-12.59$ & $<0.01$ & 0 & $t(5)=-13.15$ & $<0.01$ \\
\hline 0.1 & $t(3)=-17.39$ & $<0.01$ & 0.1 & $t(9)=-7.43$ & $<0.01$ \\
\hline 0.2 & $\begin{array}{l}t(12)=- \\
17.39\end{array}$ & $<0.01$ & 0.2 & $t(21)=-12.27$ & $<0.01$ \\
\hline 0.3 & $\begin{array}{l}t(22)=- \\
13.35\end{array}$ & $<0.01$ & 0.3 & $t(13)=-7.02$ & $<0.01$ \\
\hline 0.4 & $t(8)=-6.58$ & $<0.01$ & 0.4 & $t(15)=-6.23$ & $<0.01$ \\
\hline 0.5 & $t(21)=-8.43$ & $<0.01$ & 0.5 & $t(14)=-2.88$ & $<0.01$ \\
\hline 0.6 & $t(19)=-5.51$ & $<0.01$ & 0.6 & $t(10)=-2.61$ & 0.03 \\
\hline 0.7 & $t(19)=-6.30$ & $<0.01$ & 0.7 & $t(13)=-7.02$ & 0.74 \\
\hline 0.8 & $t(15)=-4.15$ & $<0.01$ & 0.8 & $t(6)=0.43$ & 0.68 \\
\hline 0.9 & $t(10)=-1.26$ & 0.24 & 0.9 & $t(17)=2.15$ & 0.05 \\
\hline 1 & $t(4)=0.87$ & 0.44 & 1 & $t(7)=2.22$ & 0.06 \\
\hline 1.1 & $t(14)=2.92$ & $<0.01$ & 1.1 & $t(26)=5.89$ & $<0.01$ \\
\hline $\begin{array}{l}\text { AC Threshold } \\
\text { (m) }\end{array}$ & t Statistic & p-value & CA Threshold (m) & t Statistic & p-value \\
\hline 0 & $t(7)=-22.29$ & $<0.01$ & 0 & $t(6)=-9.14$ & $<0.01$ \\
\hline 0.1 & $t(2)=-20.56$ & $<0.01$ & 0.1 & $t(8)=-7.11$ & $<0.01$ \\
\hline 0.2 & $t(9)=-17.08$ & $<0.01$ & 0.2 & $t(13)=-9.43$ & $<0.01$ \\
\hline 0.3 & $t(15)=-9.53$ & $<0.01$ & 0.3 & $t(37)=-15.16$ & $<0.01$ \\
\hline 0.4 & $t(15)=-6.55$ & $<0.01$ & 0.4 & $t(17)=-11.43$ & $<0.01$ \\
\hline 0.5 & $t(20)=-6.21$ & $<0.01$ & 0.5 & $t(11)=-3.68$ & $<0.01$ \\
\hline 0.6 & $t(14)=-4.62$ & $<0.01$ & 0.6 & $t(22)=-7.00$ & $<0.01$ \\
\hline 0.7 & $t(11)=-3.26$ & $<0.01$ & 0.7 & $t(18)=-5.29$ & $<0.01$ \\
\hline 0.8 & $t(11)=0.281$ & 0.78 & 0.8 & $t(19)=0.02$ & 0.98 \\
\hline 0.9 & $t(10)=-0.07$ & 0.94 & 0.9 & $t(19)=1.07$ & 0.3 \\
\hline 1 & $t(6)=2.47$ & 0.05 & 1 & $t(9)=2.22$ & 0.05 \\
\hline 1.1 & $t(21)=2.86$ & $<0.01$ & 1.1 & $t(33)=7.86$ & $<0.01$ \\
\hline
\end{tabular}


MPD WITH CHILDREN AND ADULTS

D)

\begin{tabular}{|c|c|c|r|l|r|}
\hline $\begin{array}{c}\text { AC Threshold } \\
(\mathbf{m})\end{array}$ & $\boldsymbol{t}$ Statistic & p-value & CA Threshold (m) & $\boldsymbol{t}$ Statistic & p-value \\
\hline 0 & $t(7)=-22.29$ & $<0.01$ & 0 & $t(6)=-9.14$ & $<0.01$ \\
\hline 0.1 & $t(2)=-20.56$ & $<0.01$ & 0.1 & $t(8)=-7.11$ & $<0.01$ \\
\hline 0.2 & $t(9)=-17.08$ & $<0.01$ & 0.2 & $t(13)=-9.43$ & $<0.01$ \\
\hline 0.3 & $t(15)=-9.53$ & $<0.01$ & 0.3 & $t(37)=-15.16$ & $<0.01$ \\
\hline 0.4 & $t(15)=-6.55$ & $<0.01$ & 0.4 & $t(17)=-11.43$ & $<0.01$ \\
\hline 0.5 & $t(20)=-6.21$ & $<0.01$ & 0.5 & $t(11)=-3.68$ & $<0.01$ \\
\hline 0.6 & $t(14)=-4.62$ & $<0.01$ & 0.6 & $t(22)=-7.00$ & $<0.01$ \\
\hline 0.7 & $t(11)=-3.26$ & $<0.01$ & 0.7 & $t(18)=-5.29$ & $<0.01$ \\
\hline $\mathbf{0 . 8}$ & $\boldsymbol{t}(\mathbf{1 1})=\mathbf{0 . 2 8 1}$ & $\mathbf{0 . 7 8}$ & $\mathbf{0 . 8}$ & $\boldsymbol{t}(\mathbf{1 9})=\mathbf{0 . 0 2}$ & $\mathbf{0 . 9 8}$ \\
\hline $\mathbf{0 . 9}$ & $\boldsymbol{t}(\mathbf{1 0})=-\mathbf{0 . 0 7}$ & $\mathbf{0 . 9 4}$ & $\mathbf{0 . 9}$ & $\boldsymbol{t}(\mathbf{1 9})=\mathbf{1 . 0 7}$ & $\mathbf{0 . 3}$ \\
\hline 1 & $t(6)=2.47$ & 0.05 & 1 & $t(9)=2.22$ & 0.05 \\
\hline 1.1 & $t(21)=2.86$ & $<0.01$ & 1.1 & $t(33)=7.86$ & $<0.01$ \\
\hline
\end{tabular}

